\title{
China: Carbon Quota and Emission Permit Can Parallel
}

\author{
Chenggang $X u^{1, a *}$, Taishou Gong ${ }^{1, b}$ \\ ${ }^{1}$ College of Economics \& Management, Three Gorges University, Yichang, Hubei, 443002, China \\ ammm98@126.com, ${ }^{\mathrm{b}} \mathrm{nnn98@sina.com}$
}

\begin{abstract}
Keywords: Carbon quota, Fuel tax, Permit system, Low carbon economy
Abstract. The emission permit system and carbon quota system should be concurrently implemented for fuel consumption. The emission license is used to distinguish the different uses of automobile.

The differential quotas of $\mathrm{CO} 2$ emissions are implemented for production or living automobiles, urban or rural users. Through a "quota" market mechanism is established, a paid transfer of carbon quota is done. If so, the excessive consumption can be curbed and it reaches the goal to control the fuel consumption and $\mathrm{CO} 2$ emissions reduction.
\end{abstract}

\section{Introduction}

We have been accustomed to the practice of free emissions of fuel consumption. The value of emissions rights are not reflected in the allocation, use and transfer. The result that the market value for the emission rights is inhibit results in the lack of the understanding about the paid use of emission rights and improving the ability of economic growth. So what we take the market operation of the "carbon reduction" and the paid transfer of emissions will contribute to the efficient use of fuel oil to achieve the suboptimal level of Pareto. When the amount of $\mathrm{CO} 2$ emissions is reduced the configuration level of production (or life) means is enhanced.

Fuel oil consumers can be divided into two categories: one kind is the users of enterprises and individual, who engaged in production activities. Another kind is the consumer group or individual, who engaged in the life. Therefore, the various types of fuel consumers are separated and the interest contact between them are designed is just to establish a starting point of the effective market mechanism of "carbon reduction".

\section{Impact for Fuel Tax}

Fuel tax will have a different impact between the users taking fuel as a factor of production and taking fuel as the living material. The assumption that there is no alternative energy, fuel for the production users is the goods with the lack of flexibility. This is because at present a large number of modern enterprises have been locked in the products and services dependent on fuel. If reduced fuel supply, enterprises would be faced with closing factory, the workers would lose their jobs.

All production users for a fuel tax is felt that when a rising tide lifts boats. Increased cost is the same situation for other companies in the same industry, and eventually to transfer to the downstream consumers. Because there is no pressure of "emission reduction"[1], they lack the power to implement improvements in fuel consumption. This increased cost may also be passed to consumers or users with no direct connection with the fuel consumption. Let them bear the cost that should not take on.

Fuel tax impact on life consumer is divided into two situations: One kind is the car as the necessity of life, such as living in the city suburbs, no more ideal means of transports. Their demand for the car is inelastic. The other is as entertainment and leisure products. Economics classify them into luxury consumption. The impact of fuel tax is a different degree on these two types of demand. For high-income people, the rise in oil prices lead to increase spending, and the effect on the amount of travel is not obvious. For low-income people, the rise in oil prices will reduce the amount of their travel. But for the latter, choosing some kind of transportation tool is only one of the many means of transport. So, because the elasticity of demand is different, their damaged situation may be different for 
each type of consumer interest. The fuel tax has no direct impact on the responsible person of carbon dioxide emissions.

\section{Emission Permit System}

The best way is to issue a permit, and allow to free transaction for the carbon quota in the market under the permit system. The emission permit system is that the government, according to the different uses or different emissions of automobiles, in accordance with the "one vehicle one card" issues vehicle emission licence, stipulates the way of quantity standard for fuel consumption to control carbon dioxide emissions. The license needs to be registered in the relevant agencies of superior government, issued and managed by local vehicle management department.

Vehicle emission license is a proof to distinguish the identity of the automobile. It is used to identify the nature of the automobile use. Such as, is the automobile of production or of life, of city or rural, of local or other place, how many $\mathrm{CO} 2$ emission level of engine, one person or one family own a one or more? Above the information is used to allocate different quotas, as shown in Fig. 1.

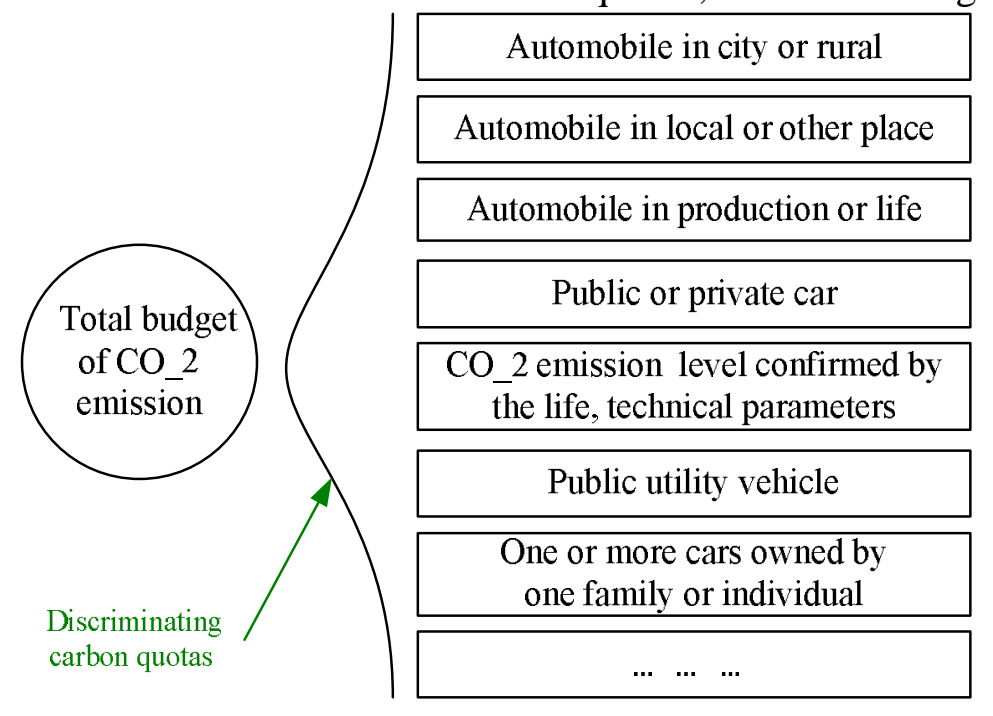

Fig.1 Carbon emission quota allocation

The license shall be used in combination with the emission quota. This uniform method of materials distribution has some similar characteristics with the function of household registration system in the Period of Planned Economy of China. In addition to in addition to the registration of family members and the localization management of the population, a more important role is to carry out the distribution of material based on the population according to household registration book. It plays a role in alleviating the contradiction between supply and demand under the shortage situation of material supply. The resident registration book contains material supply quantity distributed by local government according to the individual quota. These quotas can not be transferred, also can not be traded in different places. Different from the registration book, the emission quota of fuel consumption under the permit system can be bought or sold; this is the inherent power of market mechanism of the "carbon reduction", as shown in Fig. 2. For consumers of the insufficient gasoline consumption, they can buy unnecessary or surplus quotas from others people in the market. For productive consumers with no fuel quota restrictions, user pay tax in accordance with the recording equipment of carbon emissions. In this way, the fuel tax system is changed to the emission permits system and emission quota system for the compensation environmental pollution. Total fuel consumption in the life could be controlled.CO2 emissions will reach the goal of the government. 


\section{Incentive Mechanism}

Our analysis for the fuel tax has recognized that the levy on fuel can only get the same psychological feeling for each type of fuel consumers. It is the reasons that fuel tax has the lack of "emission reduction pressure". So the benefit of the parallel use of the emission permit system and of carbon quota system is:

(1)On the car of life, in the range of the quota consumption is not taxed, the consumption outside the quota is only taxed. The life consumer of the holding license will generate the price difference within and outside a quota, as is shown in Fig. 2.



Fig.2 Emission quota transfer mechanism

A man who holds a surplus quota can sell the quota to who is not got satisfied consumption, to get extra benefits because of "reduce travel". Although these buyers need to spend money to buy other people's quota, they increase the diversity of the life and meet the needs of the life quality. Appropriate adding in costs is acceptable to them. (If the government could make quota feasible and reasonable). Therefore, this transaction for both buyers and sellers are willing to do. Taxes outside a quota are no great loss for high-income groups, just to limit the number of invalid consumption. Let the groups who enjoy more number of luxury consumption bear more environmental compensation costs.

(2)On the automobiles as the production, although increased in use-cost, but a certain tax will encourage owners to use the vehicle of energy conservation and emissions reduction and the technology, What tax rate for production is lower than one for life is because fuel demand on production is rigid, the technology development and use of energy conservation and emissions reduction need a certain period. Production users than the consumers have fewer choices. And costs will eventually be transferred to the downstream business or consumers. So it is not conducive to improve economic benefits on the whole social.

From the expectation of the policy objectives, implementation of the permit system for the identification of the vehicle and the distinction for the production use or life, achieve differential treatment through differential tax rate. So both the emission tax system and the permit system are incentive. The use- costs of life consumers and production users will be better than before the implementation of the permit system, but the effect of the policy will promote them to develop new technology, actively adopt new energy and energy-saving products, so the effect is able to achieve total control for carbon emissions. So, the final result is to reach the goals of energy conservation and emissions reduction.

In the process of industrialization and urbanization, whether posses car, or what style of the car roughly are divided into two types of income of Chinese residents [2]. If we are based on different emissions of the engine and then distribute with different fuel quota, the effect of market transactions will be further strengthened. After the quota, gasoline for ordinary consumers is an elastic commodity; permit's quota should be the bottom line to meet the personal driving preference at the leisure time. But at other times they can change for other means of transport. When the demand for entertainment is rising it will become the source for the research and development of emission reduction technology 
and form a competitive situation between the manufacturers of power machinery. In a sense, the effect of the implementation of the permit system is actually to levy on emissions, not on fuel oil.

\section{Related issues}

There are still many technical problems to be studied in the quota distribution under the license:

(1)It is advisable to the quota standards how much in life consumption. How quota is allocated to avoid the validity of the license out of quota. The quotas setting should be scientific and reasonable. It does not affect the living standards of high income, but also to take care of the general income class to enjoy the diversity of life needs. It should be fair and transparent to avoid restricted by other interest groups.

(2)In addition to that the market transactions of carbon quota can be carried out in accordance with the traditional way of ordinary Chinese residents, it also be able to use Internet technology to achieve online transactions. Therefore, a high quality requirement for the information technology of the trading system is put forward to guarantee transaction security, reliability and real-time.

(3)The detection technology means and $\mathrm{CO} 2$ emission standards for engine should be to closely follow the development and changes in the international situation. They play the role of encouraging innovation, spur lagging behind, inspire progress, so that people can see the world's most advanced energy-saving environmentally, friendly vehicles on the road in China .So the important link needs to be completed in the background of the certification by domestic and international authoritative organization, in order to avoid being administrative intervention.

(4)The vehicle travel recorder in Fig. 2 is only a representative of the advanced emissions technology set by our. In reality, it should include many technical parameters, such as driving range, vehicle life, detection parameters, and $\mathrm{CO} 2$ emissions and so on, and may be other hardware form. Related technology is a challenge to China's technological strength.

The introduction of a system often has the meaning of its political economy. What a permit system we put forward is based on the premise that the Implementation Mechanism Joint (JI) is to take effect. The unilateral emission reduction will damage the interests of a country. The quota should be kept moderate relations with the world' total emission under permit system. "Car manufacturing power" like China, if the fuel consumption restrictions were too strict, would inhibit the growth of related industries, be not conducive to the development of national economy and deviate from the goal of overall welfare maximizing of the country[3].

\section{Conclusion}

The improved practical significance above indicate: the demand caused by the shortage of quota consumption will promote the development of environmental protection industry related to emission reduction. Consumers only use the products of energy conservation and emissions reduction to replace the traditional products to maintain and improve the original level of consumption, therefore the market mechanism for "carbon emissions"can play well the policy effect of environmental protection, It is conducive to improving the social welfare and the world's interests.

\section{References}

[1] J.R. Fu, S.F. Cao, Tax Policy Issues and Reform Ideas for China's Energy Saving and Emission Reduction. J.Financial Monthly. 02(2013):23-26.

[2] F. Zhang, Z.J. Li, Regional Differences in Energy Saving and Emission Reduction in our Country and Countermeasures.J.Macroeconomic Management; 08( 2012):12-16.

[3]H.M. Bao, Research on Technology Innovation Strategy under the Mode of Low Carbon Economy.J.Scientific Management Research, 04(2013):45-47. 